\title{
Leftventricular function disturbances in patients with acute ischemic stroke: prognostic and therapeutic implications
}

G. Siedler, K. Sommer, K. Macha, L. Breuer, S. Schwab, B. Kallmünzer.

University Hospital Erlangen, Department of Neurology, Erlangen, Germany.

\section{Background}

Leftventricular Dysfunction (LVD) in ischemic stroke constitutes a source of detrimental pathophysiologic cascades, including worsening of cerebral tissue oxygenation and hemodynamic impairment, which may affect safety and efficacy of intravenous thrombolysis and endovascular thrombectomy.

Methods

Clinical cohort study among patients with ischemic stroke and acute recanalisation therapies between 2006 and 2016 at a universitary stroke center.

Results

1209 patients were included, 375 (31\%) had LVD (tab.1+2).

\begin{tabular}{|l|c|c|c|}
\hline Age (years) & $\begin{array}{c}\text { Pat. normal } \\
\text { LVEF, n=834 }\end{array}$ & $\begin{array}{c}\text { LVD patients, } \\
n=375\end{array}$ & $p$-value \\
\hline Women & $72(20-100)$ & $79(22-101)$ & $p<0.001$ \\
\hline art. Hypertension & $682(82 \%)$ & $326(87 \%)$ & $n . s$. \\
\hline Diabetes mellitus & $215(26 \%)$ & $127(34 \%)$ & $p<0.05$ \\
\hline atrial fibrillation & $265(32 \%)$ & $214(57 \%)$ & $p<0.001$ \\
\hline premRS & $0(0-5)$ & $1(0-5)$ & $p<0.001$ \\
\hline $\begin{array}{l}\text { symptom onset to } \\
\text { needle (min) }\end{array}$ & $154(0.6-3876)$ & $147(17-1800)$ & $n . s$. \\
\hline days in hospital & $8(1-54)$ & $9(1-35)$ & $p<0.01$ \\
\hline treatment at ICU & $100(12 \%)$ & $43(11 \%)$ & $n . s$. \\
\hline mRS after 90d & $2(0-6)$ & $3(0-6)$ & $p<0.001$ \\
\hline mortality after 90d & $66(8 \%)$ & $66(18 \%)$ & $p<0.001$ \\
\hline
\end{tabular}

tab. 1: clinical data of patients

LVD is an independent predictor for unfavorable outcome (tab. 3). Nevertheless, NIHSS showed a significant improvement after treatment, and complication rate and recanalisation rate of large vessel occlusion did not differ (fig.1-3).

\begin{tabular}{l|l|l|}
\hline LVD & $\begin{array}{l}\text { NIHSS at } \\
\text { discharge, } p \text {-value }\end{array}$ & $\begin{array}{l}\text { mRS after 90days }>2, \\
p \text {-value }\end{array}$ \\
\hline age & $p<0.01$ & $p<0.05$ \\
\hline premRS & n.s. & $p<0.001$ \\
\hline Time to intervention & $p<0.01$ & $p<0.001$ \\
\hline Atrial fibrillation & $p<0.01$ & n.s. \\
\hline tab. 3: multivariate regression model for unfvorable outcome & n.s. \\
\hline
\end{tabular}

\begin{tabular}{|l|c|}
\hline & $\begin{array}{c}\text { Patients with LVD } \\
(\mathbf{n = 3 7 5 )}\end{array}$ \\
\hline Known LVD & $121(32 \%)$ \\
\hline $\begin{array}{l}\text { (N)STEMI at } \\
\text { admittance }\end{array}$ & $70(19 \%)$ \\
\hline $\begin{array}{l}\text { LVEF in } \\
\text { echocardiography } \\
\text { during stay in hospital: }\end{array}$ & \\
\hline - LVEF 35 - 50\% & $228(19 \%)$ \\
\hline - LVEF 30 - 25\% & $33(3 \%)$ \\
\hline - LVEF <25\% & $44(4 \%)$ \\
\hline
\end{tabular}

\section{Conclusion}

LVD is an indepentent predictor for unfavorable outcome in ischemic stroke, whereas no evidence for impairement of safety and efficiacy of treatment was found.
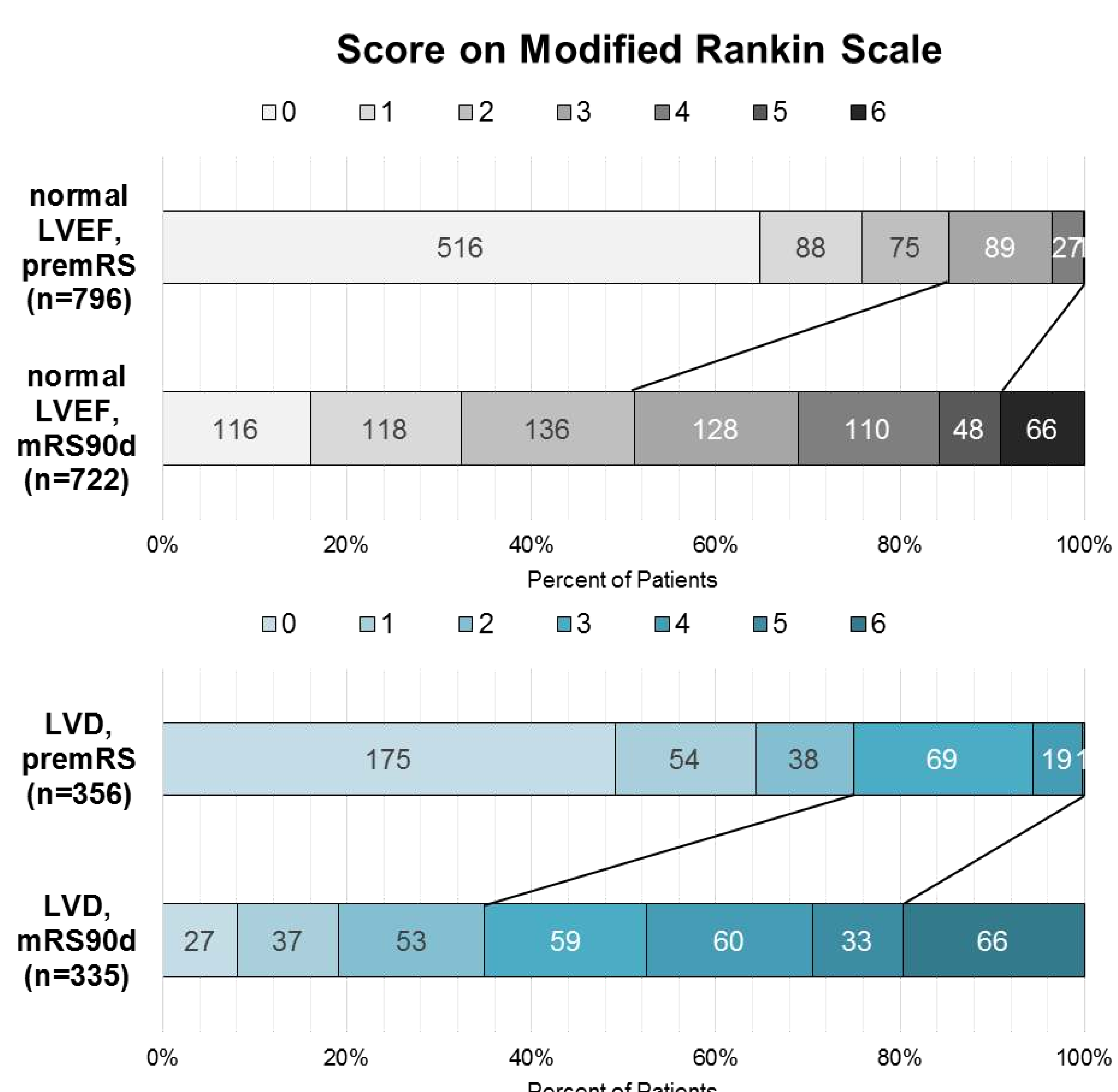

fig. 1: $\mathrm{mRS}$ of patients with and without LVD prior to stroke and after 90 days

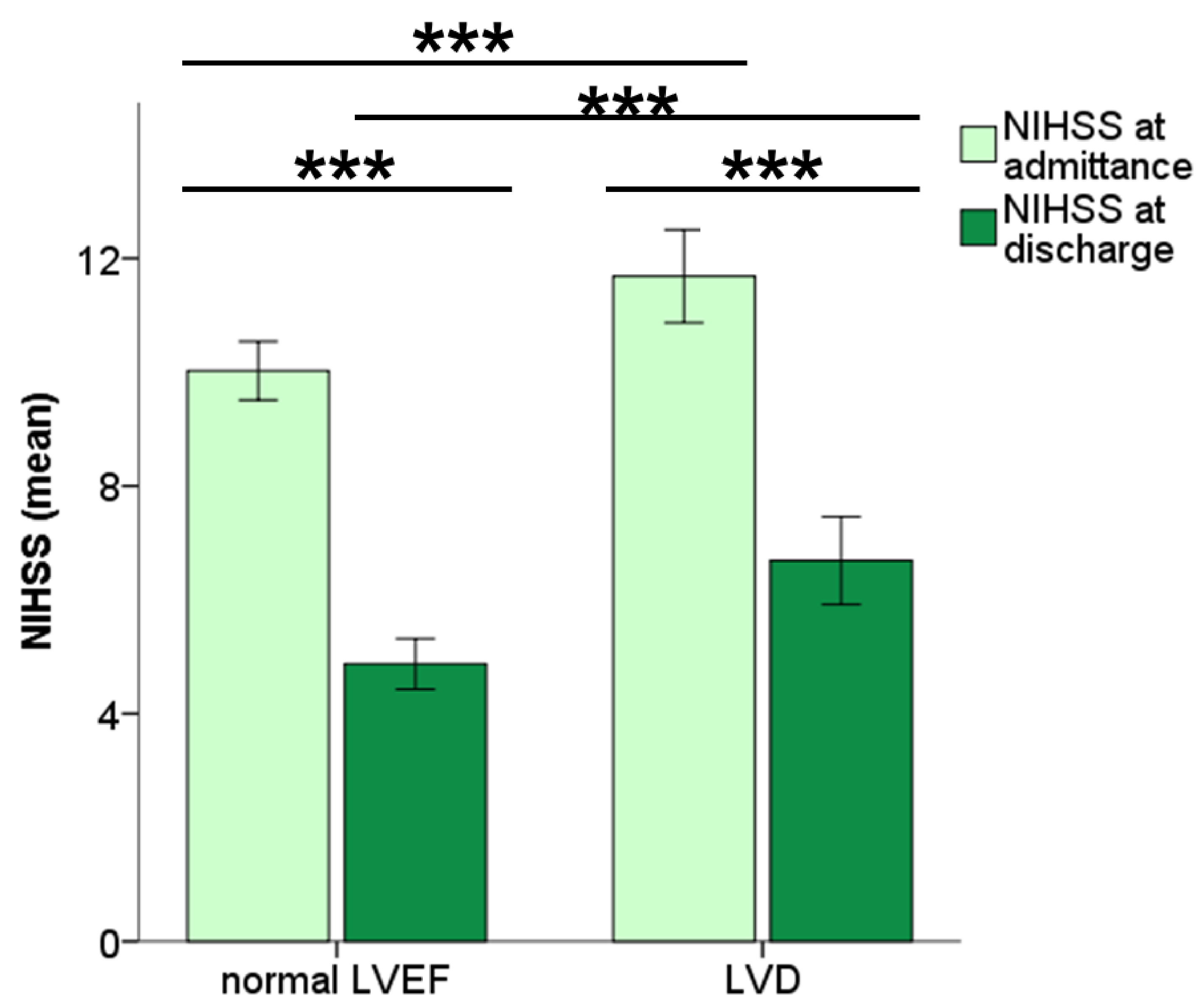

fig. 2: LVD patients had higher NIHSS at admittance at discharge, but show a clear improvement after treatment
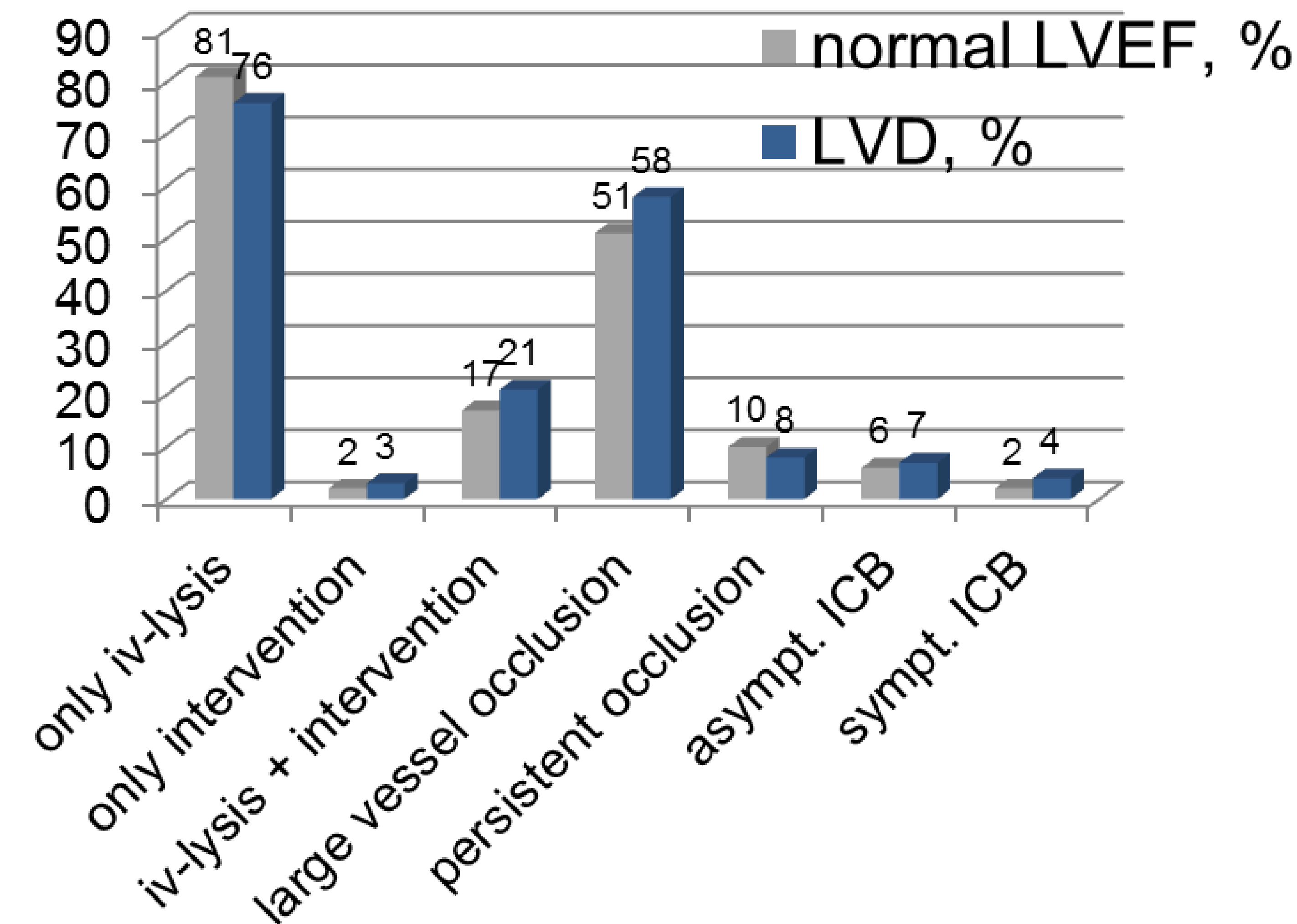

fig. 3: treatment, successfull recanalisation and complication s did not differ in LVD patients 